\title{
Representações sobre
}

\section{corpo e sexualidade de profissionais de saúde que atendem mulheres com HIV/AIDS}

\author{
Kátia Maria Barreto Souto \\ Orientador: Profa. Dra. Berlindes Astrid Küchemann \\ Curso: Mestrado em Sociologia \\ Data da defesa: 30.11.2010
}

\begin{abstract}
A dissertação apresenta uma análise das representações de corpo e sexualidade de profissionais de saúde de Brasília, considerando o contexto da feminização da AIDS e as vulnerabilidades femininas para a infecção pelo HIV. Tais representações foram apreendidas a partir da reflexão teórica e da pesquisa de campo realizada em dois centros de saúde de Brasília que atendem mulheres com HIV e AIDS junto aos profissionais de saúde, tendo como referencial as representações sociais de corpo e sexualidade. A perspectiva teóricoconceitual utilizada permitiu abordar o tema relacionando com as categorias de corpo, sexualidade, gênero e prática de saúde.
\end{abstract}

O objetivo deste trabalho foi analisar se as representações de corpo e sexualidade de profissionais de saúde que atendem mulheres com HIV/AIDS contribuem para a vulnerabilidade feminina à AIDS. Percebeu-se que as práticas de saúde dos profissionais de saúde expressam valores culturais sobre corpo e sexualidade que, no atendimento, revelam limitações e vulnerabilidades ao cuidado da saúde das mulheres. As vulnerabilidades femininas à infecção pelo HIV perpassam também as práticas de cuidado preconizadas pelos profissionais e pela organização dos serviços de atenção à saúde das mulheres e homens.

Por fim, o trabalho destaca a importância da abordagem de gênero e das representações sociais de corpo e sexualidade na formação dos profissionais de saúde para mudanças nas práticas de saúde, favorecendo a prevenção das DST/ HIV/AIDS entre as mulheres.

Palavras-chave: corpo; sexualidade; representações; profissionais. 